\title{
Fertility in a patient diagnosed with klinefelter syndrome: a rare case report
}

\begin{abstract}
Klinefelter syndrome (KS) is the most common sex-chromosome disorder (47, XXY) affecting men. This syndrome is usually characterized by hypogonadism, androgen deficiency, and azoospermia. We present here a case of a 36year-old male who didn't experience any health problems, and he was married and had three children. Eleven years later, he showed problems with fertility, decreased sexual libido and erection with intermittent testicular pain. Full examination, laboratory, and radiological investigations were done and confirmed KS. This settles the possibility of biological fatherhood in KS patients and proves wide variations in the prognosis of these cases in regard to fertility.
\end{abstract}

Keywords: klinefelter syndrome, fertility, biological fatherhood.
Volume 7 Issue 4 - 2019

\author{
Mariann Al-Jehani,' Faisal Al-Husayni, ${ }^{2}$ Salwa \\ Alaidarous ${ }^{2}$ \\ 'College of Medicine, King Saud Bin Abdulaziz University for \\ Health Sciences, National Guard Hospital, Saudi Arabia \\ ${ }^{2}$ Department of Medicine, King Saud Bin Abdulaziz University \\ for Health Sciences, National Guard Hospital, Saudi Arabia \\ Correspondence: Salwa Alaidarous, Department of Medicine, \\ King Saud Bin Abdulaziz University for Health Sciences, National \\ Gaurd Hospital, Saudi Arabia, Email Sali_al@hotmail.com, \\ Aidarouss@ngha.med.sa
}

Received: July 15, 2019 | Published: August 09, 2019

\section{Introduction}

Klinefelter syndrome is the most common sex-chromosome disorder (47, XXY) affecting men. ${ }^{1}$ The prevalence of KS may vary across different populations with a higher prevalence in Australia. ${ }^{2}$ Most men with KS go through life undiagnosed, only $25 \%$ are diagnosed and only a few of these occur before puberty. Underdiagnosis of these cases is attributed to substantial variation in the clinical presentation. ${ }^{1}$ Common features of KS are hypogonadism, androgen deficiency, and azoospermia. Additionally, most men with KS suffer from some degree of learning disability and may have various kinds of psychiatric problems. Furthermore, long-term hypogonadism is associated with more fat and less muscle mass and diminished bone mineral mass, as well as increased risk of metabolic consequences, such as type 2 diabetes and the metabolic syndrome. ${ }^{3}$ Klinefelter syndrome affects testicular function. This has been known since the first description of the syndrome by Klinefelter et al. $^{4}$ in 1942. There is progressive loss of germ cells that starts in fetal life, continues during infancy, and accelerates through puberty. This leads to fibrosis and hyalinization of seminiferous tubules as well as hyperplasia of Leydig cell. These changes ultimately result in small firm testes (typically $<3 \mathrm{ml}$ ) seen in adults and azoospermia. In parallel with this, the gonadotrophins rise to the greatly elevated levels seen in adults with KS. ${ }^{5}$ At the beginning of puberty, which in general occurs at a normal age, testes grow a little but subsequently shrink with progressive degeneration of the testicular environment. ${ }^{6}$ Klinefelter's syndrome is usually characterized by infertility. So, fertility preservation might best be proposed to adolescent Klinefelter patients just after the onset of puberty when it is possible to collect a semen sample and when the patient is able to consider alternative options to achieve fatherhood. ${ }^{7}$ There are only few old reports of spontaneous proven fatherhoods among KS men. ${ }^{8,9}$ We present here a subject with KS who naturally fathered three children.

\section{Case presentation}

A 36year- old male sought out medical help after having issues with fertility. The patient's history shows that he was born at term following an uncomplicated pregnancy and delivery. He had a normal childhood and went through puberty without any noticeable delays or abnormalities. He was married in 2002 and fathered three children, but noted that he didn't experience any symptoms or health problems during his marriage. His wife and the three children passed away unexpectedly. After remarrying in 2011, the patient complained of exhaustion, weakness in muscles as well as extreme coldness in his extremities and mentioned that it was severe enough that he required winter clothing in 35 Celsius degree weather. During his second marriage he began to have issues with fertility, intermittent periods of decreased sexual libido as well as not being able to sustain an erection. Since 2012, the patient has been complaining of intermittent testicular pain; he expressed the severity by stating that it was extremely difficult to bend over. The patient denied any past surgeries, other medical issues, and consanguinity. $\mathrm{He}$ also mentioned that both wives and children were free of any health problems. In 2014, the patient sought the help of an endocrinologist in National Guard Hospital. He was referred for semen analysis, hormone profile test, testicular ultrasound, MRI scan, and karyotype. The semen analysis was unremarkable except for a low volume of $1.3 \mathrm{ml}$. Furthermore, the hormone profile reported testosterone to be on the low side at 12.8 and $9.5 \mathrm{nmol} / \mathrm{L}$ consecutively. The results also revealed the patient had high levels of FSH and $\mathrm{LH}$ at 32.96 and $21.72 \mathrm{mIU} / \mathrm{mL}$, respectively. The testicular ultrasound showed that both testes were smaller in size with very heterogeneous echotexture and multiple well-defined hypoechoic heterogeneous areas scattered within both testes. He was then referred for an MRI to rule out any neoplastic lesions. The MRI of the brain, pituitary and cervical spine was normal. In addition, the cytogenetic investigation revealed that the patient has a male chromosome complement with an additional $\mathrm{X}$ chromosome in all cells investigated. The results of the karyotype confirmed the suspected diagnosis of Klinefelter syndrome. There is no known family history of Klinefelter or any other syndromes. At the start of 2015, the patient commenced treatment on testosterone cypionate (Depo-Testosterone) $250 \mathrm{mg}$ intramuscular injection every 2 weeks. His testosterone levels after starting treatment were 11.9 and $42 \mathrm{nmol} / \mathrm{L}$ consecutively. After 3years, his most recent testosterone level was $25.77 \mathrm{nmol} / \mathrm{L}$. In 2018 , he was placed on a new treatment plan with testosterone undecanoate (Nebido) $1000 \mathrm{mg} / 4 \mathrm{ml}$ injection every 3 months. The patient has received hormone replacement medication now for 3 years although has yet to report significant symptom improvement. 


\section{Discussion}

To the best of our knowledge this patient represents an uncommon occurrence of normal fertility and biological fatherhood of three children in Klinefelter's syndrome. The patient was married approximately at the age of 20years. He didn't experience any symptoms or health problems during his marriage and fathered three children. At the age of 31years, during his second marriage, he showed problems with fertility and some clinical manifestations like exhaustion, weakness in muscles, as well as extreme coldness in his extremities, intermittent periods of decreased sexual libido, inability to sustain an erection, and intermittent testicular pain. In fact, males with KS do not appear different from other males, and they may have mild to severe symptoms depending on the amount of testosterone needed for a specific age or developmental stage and the amount of testosterone the body makes. ${ }^{10}$ Early presentation of severe manifestations usually occurs in males with poly-X Klinefelter syndrome, those having more than one extra X chromosome, ${ }^{11}$ which is not the case in our patient (he was $47 \mathrm{XXY}$ ).

Suggestive laboratory changes of $\mathrm{KS}$ in this case were a combination of low semen volume, testosterone levels, and high FSH and LH levels. In addition, ultrasound examination revealed suggestive signs of small testes with very heterogeneous echo-texture and multiple well-defined hypo-echoic heterogeneous areas scattered within them. The results of the karyotyping revealed that the patient has a male chromosome complement with an additional X chromosome in all cells investigated, which confirmed the suspected diagnosis of Klinefelter syndrome. The onset of puberty in adolescents with KS leads to progressive degeneration of the testicular environment. The impact of the subsequent tissue degeneration on fertility potential of patients with KS is unknown. Although the vast majority of men with non-mosaic KS are azoospermic, motile sperms in the ejaculate and even spontaneous pregnancies resulting from KS fathers have been described, although such cases are rare. Moreover, Klinefelter mosaics $(47, \mathrm{XXY} / 46, \mathrm{XY})$ are less severely affected and the chance of finding sperm in the ejaculate in these males is significantly higher than in non-mosaic cases. ${ }^{6}$

Most KS patients are azoospermic at adult age because of a massive germ cell loss. However, the timing when this germ cell loss starts is not known. ${ }^{12}$ The reported normal fertility and biological paternity in this case might be attributed to less hyalinization and tubular damage than is usual in this syndrome, which means that he might have had a higher sperm count than most patients with $\mathrm{KS} .{ }^{9}$ A few cases of fertility in KS have been reported. One patient was reported to have all the clinical and laboratory signs of KS except for a testicular volume of $10 \mathrm{ml} .{ }^{9} \mathrm{He}$ fathered two children naturally after receiving hormone replacement therapy. The fertility seen might have been attributed to the large testicular volume which indicates less hyalinization and tubular damage. In addition, the initiation of testosterone therapy at the onset/demonstration of progressive testicular failure at age of 17 may have increased the likelihood of fertility. ${ }^{9}$ The lack of significant improvement after hormone therapy seen in our patients' case may be due to the initiation of therapy at a later age compared to this patient. ${ }^{9}$ Another KS patient demonstrated fertility due to a mutation of fibroblast growth factor receptor 3 gene $\left(\mathrm{FGFR}_{3}\right)$ which is believed to have played a role in spermatogonia proliferation and/or prevention of apoptosis giving germ cells a selective advantage. ${ }^{13}$ The mutation

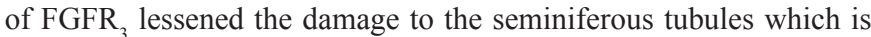
usually seen in KS patients. That patient had a large testicular volume at $8 \mathrm{ml}$, normal $\mathrm{LH}$ and testosterone levels, but high FSH levels and detectable inhibin B. These finding differ from the typical results found in KS patients. ${ }^{13}$

\section{Conclusion}

The described case report settles the possibility of biological fatherhood in 47, XXY patients and proves wide variations in the prognosis of these cases in regard to fertility. Further studies may help in understanding and preserving fertility in patients suffering from KS.

\section{Acknowledgments}

None.

\section{Conflicts of interest}

The authors declare that there are no conflicts of interest.

\section{Funding}

None.

\section{References}

1. Bojesen A, Juul S, Gravholt CH. Prenatal and postnatal prevalence of Klinefelter syndrome: a national registry study. The Journal of clinical endocrinology and metabolism. 2003;88(2):622-626.

2. Herlihy AS, Halliday JL, Cock ML, et al. The prevalence and diagnosis rates of Klinefelter syndrome: an Australian comparison. The Medical journal of Australia. 2011;194(1):24-28.

3. Høst C, Skakkebæk A, Groth KA, et al. The role of hypogonadism in Klinefelter Syndrome. Asian Journal of Andrology. 2014;16(2):185-191.

4. Smyth CM, Bremner WJ. Klinefelter syndrome. Archives of internal medicine. 1998;158(12):1309-1314.

5. Aksglaede L, Wikstrom AM, Rajpert-De Meyts E, et al. Natural history of seminiferous tubule degeneration in Klinefelter syndrome. Human reproduction update. 2006;12(1):39-48.

6. Franik S, Hoeijmakers Y, D'Hauwers K, et al. Klinefelter syndrome and fertility: sperm preservation should not be offered to children with Klinefelter syndrome. Human reproduction (Oxford, England) 2016;31(9):1952-1959.

7. Rives N, Milazzo JP, Perdrix A, et al. The feasibility of fertility preservation in adolescents with Klinefelter syndrome. Human reproduction (Oxford, England). 2013;28(6):1468-1479.

8. Warburg E. A fertile patient with Klinefelter's syndrome. Acta endocrinologica. 1963;43:12-26.

9. Laron Z, Dickerman Z, Zamir R, et al. Paternity in Klinefelter's syndrome - a case report. Archives of andrology. 1982;8(2):149-151.

10. Visootsak J, Aylstock M, Graham JM. Klinefelter syndrome and its variants: an update and review for the primary pediatrician. Clinical pediatrics. 2001;40(12):639-651.

11. Sahin Y, Ozcan A. First Report of Two Rare Entities in a Family: 49,XXXXY and 45, X. Journal of pediatric genetics. 2017;6(3):174-176.

12. Van Saen D, Vloeberghs V, Gies I, et al. When does germ cell loss and fibrosis occur in patients with Klinefelter syndrome? Human reproduction (Oxford, England). 2018;33(6):1009-1022.

13. Juul A, Aksglaede L, Lund AM, et al. Preserved fertility in a non-mosaic Klinefelter patient with a mutation in the fibroblast growth factor receptor 3 gene: Case Report. Human Reproduction. 2007;22(7):1907-1911. 